\title{
Investigation of antioxidant and anti-glycation properties of essential oils from fruits and branchlets of Juniperus oblonga
}

\author{
Seyed A. Emami,,"1 Sedigheh Asgary, ${ }^{2}$ Gholam A. Naderi, ${ }^{2}$ \\ Mohammad R. S. Ardekani, ${ }^{3}$ Sanaz Aslani, ${ }^{4}$ Atousa Airin, ${ }^{4}$ \\ Taghi Kasher, ${ }^{4}$ Amirhossein Sahebkar ${ }^{5}$
}

\author{
${ }^{1}$ Department of Pharmacognosy, School of Pharmacy, Mashhad University of \\ Medical Sciences, Iran, \\ ${ }^{2}$ Isfahan Cardiovascular Research Center, Isfahan University of Medical \\ Sciences, Iran, \\ ${ }^{3}$ Department of Pharmacognosy, School of Pharmacy, Tehran University of \\ Medical Sciences, Iran, \\ ${ }^{4}$ School of Pharmacy, Isfahan University of Medical Sciences, Iran, \\ ${ }^{5}$ Biotechnology Research Center and School of Pharmacy, Mashhad University \\ of Medical Sciences, Iran.
}

\begin{abstract}
Plants represent the best and most extensively studied source of natural antioxidants. The present study investigated the antioxidant and anti-glycation properties of different concentrations of essential oils obtained from fruits and branchlets of Juniperus oblonga M. Bieb., Cupressaceae, using different assays. The essential oils were obtained by steam distillation of the branchlets of male tree (BMT), branchlets of female tree (BFT) and fruits of $J$. oblonga. Compositional analysis of oils was performed using a gas chromatography-mass method. Antioxidant activity was assessed using linoleic acid peroxidation, peroxyl radical mediated hemolysis of red blood cells (RBC) and low-density lipoprotein (LDL) oxidation assays. Anti-glycation properties of oils were evaluated using hemoglobin and insulin glycation assays. Seventeen, eighteen and fifteen compounds were identified in the BMT, BFT and fruit oil, which represented 82.51, 55.69 and $96.89 \%$ of the total oils, respectively. $\alpha$-Pinene was the major component of all three oils. All three oils possessed antioxidant effects against LDL oxidation, linoleic acid peroxidation and peroxyl radical mediated RBC hemolysis. Anti-glycation activities against hemoglobin and insulin glycation were also observed from all tested oils. Overall, there was no unique pattern of dose-dependence for the antioxidant properties of oils in different employed systems. The findings of this study suggest that essential oils from fruits and branchlets of $J$. oblonga possess antioxidant and anti-glycation properties. Therefore, these oils might be of therapeutic efficacy against diabetes and cardiovascular disease.
\end{abstract}

Revista Brasileira de Farmacognosia Brazilian Journal of Pharmacognosy 22(5): 985-993, Sep./Oct. 2012

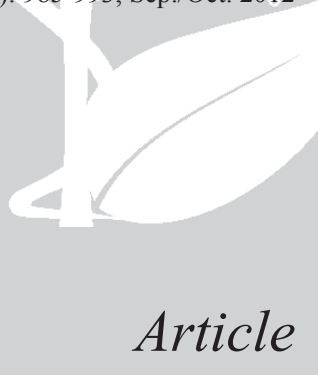

Received 26 Aug 2011 Accepted 29 Jan 2012 Available online 12 Apr 2012

$$
\begin{array}{r}
\text { Keywords: } \\
\text { antioxidant } \\
\text { essential oil } \\
\text { Juniperus oblonga } \\
\text { Cupressaceae } \\
\text { protein glycation }
\end{array}
$$

ISSN 0102-695X http://dx.doi.org/10.1590/S0102695X2012005000045

\section{Introduction}

Plants represent the best and most extensively studied source of natural antioxidants. A plethora of epidemiological evidence has supported the inverse relationship between consumption of diets rich in fruits and vegetables and incidence of numerous disorders such as cancer, cardiovascular disease and etc (Kang et al., 1996).

Free radicals are highly reactive molecules which can severely damage the structure of biomolecules such as DNA and proteins, thereby leading to impairment or even loss of their vital biological functions. One of the main targets of free radicals are unsaturated fatty acids that are present in the biological membranes. Oxidation of these fatty acids by pro-oxidant species impairs permeability, structure and function of membrane and mediates the pathogenesis of a wide variety of disorders (van Ginkel \& Sevanian, 1994). An important outcomes of free radical damage is low-density lipoprotein (LDL) oxidation which has a pivotal role in triggering atherosclerosis and subsequent development of cardiovascular disease (Berliner et al., 1995). Another important sequelae of oxidative stress is glycation of proteins which is a process implicated in aging, LDL oxidation and diabetic complications (Monnier, 1990; Wolff, 1993, Selvaraj et al., 2002).

Development of oxidative stress and its 
complications could be retarded by antioxidants. In recent years, there has been a world-wide interest on finding natural antioxidants from plant sources. These natural antioxidants could serve as safe alternatives to synthetic antioxidants such as butylated hydroxy anisole (BHA) and butylated hydroxy toluene (BHT) which are suspected to exert adverse reactions such as carcinogenesis and hepatotoxicity (Wichi, 1986; Grice, 1988).

Juniperus oblonga M. Bieb. is a rather low and dioecious evergreen tree. This plant belongs to the family Cupressaceae, and Oxycedrus subgenus of the genus Juniperus. J. oblonga is found in Iran (Persian name: Chatanah), Turkey, and the Caucasus. Ripe berries of $J$. oblonga have been reported for their diuretic and anti-scorbutic effects (Komarov, 1968). Reports on the phytochemistry and biological activities of this plant have been very scarce. In two previous studies, Emami and colleagues have indicated that the essential oils of $J$. oblonga possess antioxidant activity (Emami et al., $2007 \mathrm{a}, \mathrm{b})$. The present study investigated the antioxidant and anti-glycation properties of essential oils obtained from fruits and branchlets of $J$. oblonga using different in vitro assays.

\section{Materials and Methods}

\section{Chemicals}

All chemicals were purchased from Merck (Germany) apart from the bovine insulin were obtained from Novo Nordisk (Denmark) and AAPH from Wako (USA).

\section{Plant material}

The branchlets of male tree (BMT), branchlets of female tree (BFT) and fruits of Juniperus oblonga M. Bieb., Cupressaceae, were collected from an area between Makidi and Vainagh, Arasbaran, East Azarbayejan province (height $1500 \mathrm{~m}$ ). The plant was identified by Dr. M. Assadi from the National Botanical Garden (Tehran, Iran). Voucher specimens of the plants (no FUMH37071) were deposited in the herbarium TARI. The plant materials were stored at $-20^{\circ} \mathrm{C}$ before use.

\section{Essential oils isolation}

Steam distillation method was applied to obtain essential oils (4 h). Afterwards, essential oils were dried over anhydrous sodium sulfate and their percentages were calculated. Specific gravity of essential oils was measured using a sensitive scale (Scaitec, Germany). In addition, specific rotation (DIP-310 digital polarimeter, Electrothermal 2200, UK) and refractive index (Abbe refractometer) were determined for each oil.

\section{Gas chromatography-mass analysis}

The GC/MS apparatus consisted of a Hewlett Packard 6890 gas chromatograph equipped with a fusedsilica column (DB-5, $30 \mathrm{~m} \times 0.25 \mathrm{~mm}$ film thickness $0.25 \mathrm{~mm}$; Agilent HP), and interfaced with a quadruple mass spectrometric detector (HP 6890). The operating conditions were: oven temperature $60-275{ }^{\circ} \mathrm{C}$ with the rate of $4{ }^{\circ} \mathrm{C} . \mathrm{min}-1$; injector mode: split injection (split ratio of 50:1; injection volume: $0.1 \mu \mathrm{L}$ ), with $\mathrm{He}$ as the carrier gas, flow rate of $2 \mathrm{~mL} \cdot \mathrm{min}^{-1}, 70 \mathrm{eV}$ ion source, $1000 \mu \mathrm{A}$ ionization current, and scan range of 30-300 atomic mass unit (AMU).

The oil components were identified from their retention indices (RI) obtained with reference to $n$-alkane series (Sigma, UK) on DB-5 column, mass spectra with those of authentic samples, composition of their mass spectra and fragmentation patters reported in literature (Adams, 2001) and computer matching with MS-data bank (Wiley Library).

A stock solution was prepared from each essential oil as follows: one hundred microliters of essential oil was added to $250 \mu \mathrm{L}$ of Tween $20(0.2 \%)$ and diluted by deionized water to a final volume of 50 $\mathrm{mL}$. The obtained mixture was shaken in ultrasonic bath (SU3 THE, Japan) for $15 \mathrm{~min}$ to obtain the stock emulsion $\left(2000 \mu \mathrm{g} \cdot \mathrm{mL}^{-1}\right)$. Different concentrations of essential oils were prepared by transferring different volumes $(10,20$ and $30 \mu \mathrm{L}$ in the LDL oxidation assay; 1, 2 and $3 \mathrm{~mL}$ in the hemoglobin and insulin glycation assays; and 40, 50 and $60 \mu \mathrm{L}$ in the linoleic acid and red blood cell hemolysis assays) of this stock emulsion to the reaction mixtures. With these volumes, final concentrations amounted to $6.25,12.5$ and 18.75 $\mu \mathrm{g} . \mathrm{mL}^{-1}$ (in the LDL oxidation assay); 200, 400 and $600 \mu \mathrm{g} \cdot \mathrm{mL}^{-1}$ (in the hemoglobin and insulin glycation assays); and 180, 220 and $260 \mu \mathrm{g} \cdot \mathrm{mL}^{-1}$ (in the linoleic acid and red blood cell hemolysis assays).

\section{Susceptibility of LDL oxidation in vitro assay}

Twelve hours-fasted blood $(100 \mathrm{~mL})$ was obtained from a local blood bank from normal healthy volunteers (25-35 years) and mixed with 50 mg.mL-1 EDTA solution $(3 \mathrm{~mL})$. The LDL fraction was isolated from whole plasma by ultracentrifugation (Beckman L100 XP, USA) through a $\mathrm{KBr}$ discontinuous gradient (Wang et al., 2006). To each ultracentrifugation tube, 9 $\mathrm{mL}$ of $1 \mathrm{mg} . \mathrm{mL}^{-1}$ EDTA solution ( $\mathrm{pH}$ 7.4) was added and then mixed with plasma/KBr mixture. EDTA was then removed by rapid filtration. Due to high volume of obtained LDL, it was dialyzed by special bag. Dialysis was performed in phosphate buffer saline (PBS) $\left(\mathrm{Na}_{2} \mathrm{HPO}_{4}\right.$ 
0.01 mol. $\mathrm{L}^{-1}+\mathrm{NaCl} 0.15$ mol. $\mathrm{L}^{-1} ; \mathrm{pH} 7.4$ ) at $4{ }^{\circ} \mathrm{C}$ for 72 $\mathrm{h}$ under nitrogen in the dark. Protein concentrations in obtained-LDL were determined by the method of Lowry (Anderson et al., 1999). LDL was oxidized using the classical copper-induced LDL auto-oxidation (Lowry et al., 1951). Incubations were carried out at $37{ }^{\circ} \mathrm{C}$ for measuring the conjugated diene formation during different times up to $210 \mathrm{~min}$. In the presence and absence of each different concentration of examined oils $(6.25,12.50$ and $18.75 \mu \mathrm{g} . \mathrm{mL}^{-1}$ ) and vitamin $\mathrm{C}$, conjugated diene formation was determined as a measure of endogenous LDL lipid peroxidation by monitoring the increase in absorbance at $234 \mathrm{~nm}$ in a Shimadzu UV-3100 scanning spectrophotometer. All experiments were performed in triplicate. Differences in lag times (minutes) for $\mathrm{Cu}^{2+}$ exposed LDL were considered as an index of oxidation (Schinella et al., 2007).

\section{Hemoglobin and insulin glycation in vitro assays}

Twelve hours-fasted blood $(100 \mathrm{~mL})$ was obtained from a local blood bank from normal healthy volunteers (25-35 years) and mixed with $50 \mathrm{mg} \cdot \mathrm{mL}^{-1}$ EDTA solution $(3 \mathrm{~mL})$. EDTA-blood samples were centrifuged $(3000 \mathrm{x} \mathrm{g})$; the clear plasma and buffy coat layers were discarded. The red blood cells (RBC) were washed with cold normal saline $\left(9.0\right.$ g. $\left.\mathrm{L}^{-1}\right)$ three times. Then, $0.5 \mathrm{~mL}$ of each washed-RBC was resuspended in $2 \mathrm{~mL}$ of phosphate buffer $\left(0.1 \mathrm{~mol}^{-\mathrm{L}^{-1}}, \mathrm{pH} 7.4\right)$ and $2 \mathrm{~mL}$ of $\mathrm{CCl} 4$ and centrifuged at $2800 \mathrm{xg}$ for $5 \mathrm{~min}$. The upper layers (containing hemoglobin) were transferred to new tubes and the hemoglobin concentrations were measured by Drabkin method (Drabkin et al., 1993). A dilution with final concentration of $0.05 \mathrm{mg} \cdot \mathrm{mL}^{-1}$ was prepared from each hemoglobin solution.

Bovine insulin (Novonordisk, Denmark) was prepared by adding phosphate buffer 0.01 mol.L $\mathrm{L}^{-1}(\mathrm{pH}$ 7.4) to obtain a final concentration of $100 \mathrm{IU} / \mathrm{mL}$. Three concentrations $(200,400$ and $600 \mu \mathrm{g} \cdot \mathrm{mL}-1)$ of each oil were tested in this assay. These concentrations were prepared by making 1,2 and $3 \mathrm{~mL}$ of the stock essential oil emulsion $\left(2000 \mu \mathrm{g} \cdot \mathrm{mL}^{-1}\right)$ to the final volume of $10 \mathrm{~mL}$ using deionised water. All experiments were performed in triplicate. The rates of hemoglobin and insulin glycation in the presence and absence of the examined oils were measured after $48 \mathrm{~h}$ incubation at room temperature (Asgary et al., 2002).

\section{Linoleic acid in vitro assay}

One hundred fifty five microliters of linoleic acid was added to $200 \mu \mathrm{L}$ of Tween $20(0.2 \%)$ and diluted by deionized water to a final volume of $50 \mathrm{~mL}$ (emulsion $\left.0.01 \mathrm{~mol} . \mathrm{L}^{-1}\right)$. The obtained mixture was shaken in an ultrasonic bath for $15 \mathrm{~min}$ (Farag et al., 1989). The obtained linoleic acid emulsion was neutralized by $\mathrm{KOH} 1$ mol.L-1 $(\mathrm{pH} 7)$ and diluted by phosphate buffer $(\mathrm{pH} \mathrm{7)}$ to a final volume of $75 \mathrm{~mL}$ (Valenzuela et al., 1986). This emulsion was used to monitor linoleic acid peroxidation in the presence and in the absence of three different concentrations of each essential oil $(480,600$ and $720 \mu \mathrm{g} \cdot \mathrm{mL}^{-1}$ ). Oxidation was initiated by addition of a $\mathrm{FeSO}_{4}$ solution (final concentration, $500 \mu \mathrm{mol} . \mathrm{L}^{-1}$ ) to a mixture of $1.5 \mathrm{~mL}$ of linoleic acid emulsion and 0.5 $\mathrm{mL}$ of $\mathrm{K}_{2} \mathrm{HPO}_{4}$. The control was treated with the same volume of the vehicle solution of the solvent; $\mathrm{K}_{2} \mathrm{HPO}_{4}$. Incubation was performed at $37^{\circ} \mathrm{C}$ for $4 \mathrm{~h}$. Linoleic acid peroxidation was monitored by absorbance changes (at $233 \mathrm{~nm}$ ) in a spectrophotometer. The percentage increased of conjugated diene between $0 \mathrm{~h}$ and $4 \mathrm{~h}$ was determined every one hour. All assays were performed in triplicate. The inhibitory effect of each oil against conjugated diene production was calculated for each hour of the test using the following formula:

$\%$ Inhibition $=[(1-($ sample absorption/negative control absorption $)] \times 100$

\section{Red blood cells hemolysis in vitro assay}

RBC were isolated by centrifugation of heparinized blood obtained from healthy donors provided by a local blood bank - and washed three times by normal saline solution. Washed-RBC was suspended to $10 \%$ hematocrit in phosphate-buffered saline. $2,2^{2}$ azobis dihydrochloride (AAPH) was used to induce RBC oxidation. The assay is based on generation of peroxyl radicals by the hydrophilic radical generator AAPH to, thereby oxidizing $\mathrm{RBC}$ and measuring the extent of RBC hemolysis by spectroscopic assay (Ljubuncic et al., 2006). Aliquots $(1 \mathrm{~mL})$ of diluted $\mathrm{RBC}$ were incubated with $1 \mathrm{~mL}$ of freshly prepared $25 \mathrm{mmol} . \mathrm{L}^{-1} \mathrm{AAPH}$ in the absence (negative control) and presence of different concentrations of $J$. oblonga essential oils (180, 220 and $\left.260 \mu \mathrm{g} \cdot \mathrm{mL}^{-1}\right)$ at $37^{\circ} \mathrm{C}$ for $2 \mathrm{~h}$. After $10 \mathrm{~min}$ centrifugation $(3000 \mathrm{x} \mathrm{g})$, the absorbance reading of supernatant was evaluated at $540 \mathrm{~nm}$. Each assay was performed for six times. The percentage of inhibitory effect of each sample against RBC hemolysis was calculated using the following formula:

$\%$ Inhibition $=[1-($ sample absorption/negative control absorption $)]) \times 100$

\section{Results and Discussion}

\section{Phytochemical analysis}

Yield values and other characteristics (specific gravity, refractive index and specific rotation) of the obtained oils have been summarized in Table 1. In the essential oils obtained from BMT, BFT and fruits of 
Juniperus oblonga, 17, 18 and 15 compounds were identified which represented $82.5,55.5$ and $96.9 \%$ of the total oils, respectively. In all three oils, monoterpene hydrocarbons were the predominant class of compounds, followed by sesquiterpene hydrocarbones and oxygenated monoterpenes. No oxygenated sesquiterpene was found in any of the analyzed oils. $\alpha$-Pinene was the major component of all three oils, constituting 27.4, 20.6 and $33.3 \%$ of BMT, BFT and fruit oil, respectively (Table 2).

Table 1. Characteristics of essential oils obtained from different parts of Juniperus oblonga.

\begin{tabular}{lcccc}
\hline & BMT oil & BFT oil & Fruit oil \\
\hline Appearance & Pale yellow & Pale yellow & 0.18 & 0.67 \\
Yield $(\mathrm{v} / \mathrm{w} \%)$ & 0.55 & 0.86 & 0.86 \\
Specific gravity $(\mathrm{g} / \mathrm{mL})$ & 0.87 & 1.48 & 1.47 \\
Refractive index & 1.47 & +31.3 & +27.7 \\
Specific rotation & +54.7 & & \\
\hline
\end{tabular}

Table 2. Chemical composition (\%) of the branchlet and fruit oils of Juniperus oblonga.

\begin{tabular}{|c|c|c|c|c|}
\hline \multirow{2}{*}{ Component } & \multirow{2}{*}{$\mathrm{RRI}^{\mathrm{a}}$} & \multicolumn{3}{|c|}{$\mathrm{RA}(\%)^{\mathrm{b}}$} \\
\hline & & BMT oil & BFT oil & Fruit oil \\
\hline$\alpha$-thujene & 935 & 3.0 & 2.4 & 2.6 \\
\hline$\alpha$-pinene & 942 & $27.4^{*}$ & $20.6^{*}$ & $33.3^{*}$ \\
\hline sabinene & 985 & 21.6 & 2.6 & 23.8 \\
\hline$\beta$-pinene & 990 & 4.4 & 4.7 & 20.8 \\
\hline$\delta$-2-carene & 1012 & 0.6 & 1.1 & - \\
\hline$\alpha$-terpinene & 1022 & - & 1.0 & 0.3 \\
\hline limonene & 1050 & $1.2 *$ & $6.0^{*}$ & $4.4^{*}$ \\
\hline$\gamma$-terpinene & 1065 & 4.4 & 1.7 & 0.8 \\
\hline isoterpinolene & 1088 & $1.9^{*}$ & $1.9^{*}$ & $1.9^{*}$ \\
\hline terpinen-4-ol & 1158 & 2.0 & $2.2^{*}$ & $0.7 *$ \\
\hline 2-undecanone miscellaneous & 1295 & 2.4 & $2.2 *$ & - \\
\hline$\alpha$-cubebene & 1350 & 3.0 & 1.2 & - \\
\hline$\beta$-elemene & 1391 & - & - & 0.3 \\
\hline E-caryophyllene & 1435 & 1.3 & 0.7 & $0.2^{*}$ \\
\hline$\gamma$-elemene & 1440 & 2.7 & 2.6 & 4.5 \\
\hline$\alpha$-humulene & 1450 & 1.7 & 0.4 & 0.1 \\
\hline AR-curcumene & 1490 & 1.8 & 2.3 & - \\
\hline germacrene D & 1492 & - & - & 1.5 \\
\hline$\beta$-bisabolene & 1510 & 2.7 & 0.9 & - \\
\hline$\gamma$-cadinene & 1535 & 0.4 & 1.0 & - \\
\hline germacrene B & 1585 & - & - & 1.7 \\
\hline monoterpene hydrocarbons & & 64.5 & 42.0 & 87.9 \\
\hline oxygenated Monoterpenes & & 2.0 & 2.2 & 0.7 \\
\hline sesquiterpene hydrocarbons & & 13.6 & 9.1 & 8.3 \\
\hline oxygenated sesquiterpenes & & - & - & - \\
\hline miscellaneous & & 2.4 & 2.2 & - \\
\hline total identified & & 82.5 & 55.5 & 96.9 \\
\hline
\end{tabular}

BMT: branchlets of male tree; BFT: branchlets of female tree; aRRI: Relative retention indices as determined on a CP-SIL 8 CB column using the homologous series of n-alkanes; bRA: Relative area (peak area relative to total peak area); *Structure was confirmed by GC-FTIR. 


\section{LDL oxidation}

Antioxidant activities of $J$. oblonga essential oils were tested against $\mathrm{Cu}^{2+}$-induced LDL oxidation. Duration of the lag phase of oxidation reaction was used as a metric for the antioxidant activity of essential oils and retardation of LDL oxidation. Vitamin C (as the positive control) substantially prolonged the lag phase from $15 \mathrm{~min}$ (in the negative control) to $165 \mathrm{~min}$. Almost all oils could prolong the lag phase of the reaction and thus possessed antioxidant activity. The antioxidant activity of the oils increased as a function of concentration. For the BMT oil, duration of lag phase was $45 \mathrm{~min}$ in the negative control sample and 45, 75 and $90 \mathrm{~min}$ for oil concentrations of $6.25,12.50$ and $18.75 \mu \mathrm{g} . \mathrm{mL}^{-1}$, respectively. Duration of lag phase was increased by BFT oil from $60 \mathrm{~min}$ to 85 $\min \left(6.25 \mu \mathrm{g} \cdot \mathrm{mL}^{-1}\right), 120 \mathrm{~min}\left(12.50 \mu \mathrm{g} \cdot \mathrm{mL}^{-1}\right)$ and 130 $\min \left(18.75 \mu \mathrm{g} . \mathrm{mL}^{-1}\right)$. With respect to the fruit oil, lag phase was prolonged from $60 \mathrm{~min}$ in the negative control sample to 75,100 and $120 \mathrm{~min}$ for oil concentrations of $6.25,12.50$ and $18.75 \mu \mathrm{g} . \mathrm{mL}^{-1}$, respectively.

\section{Hemoglobin glycation}

BMT, BFT and fruit oils of $J$. oblonga were found to possess inhibitory activity against insulin glycation at all tested concentrations. BMT oil had the highest anti-glycation activity and this was true for all three assessed concentrations. The highest inhibitory activity of all essential oils was at $200 \mu \mathrm{g} \cdot \mathrm{mL}^{-1}$ and decreased by increasing oil concentration to 400 and 600 $\mu$ g. $\mathrm{mL}^{-1}$ (Figure 1).

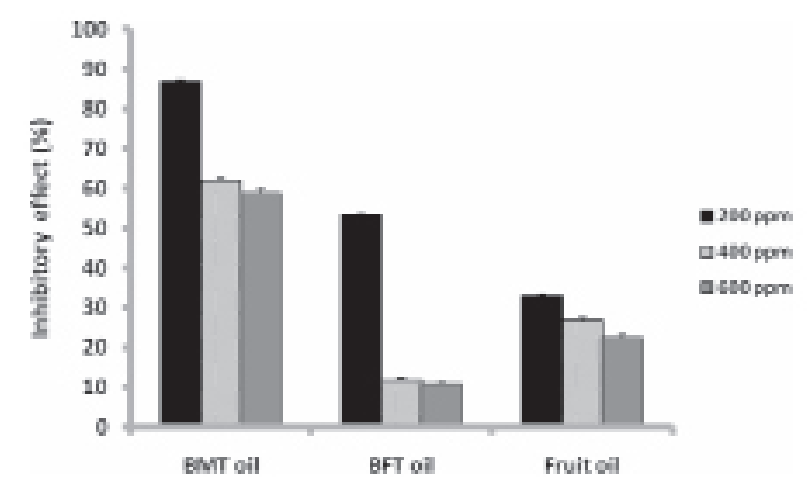

Figure 1. Inhibitory effects of Juniperus oblonga essential oils against hemoglobin glycation. BMT: branchlets of male tree; BFT: branchlets of female tree.

\section{Insulin glycation}

Promising anti-glycation effects were observed from BMT, BMT, BFT and fruit oils of J. oblonga against insulin glycation at all tested concentrations. Overall, BMT oil had the highest inhibitory activity. For BMT and fruit oils, the anti-glycation activity was augmented with increasing concentration while no direct association between oil concentration and inhibitory effect was observed for BFT oil (Figure 2).

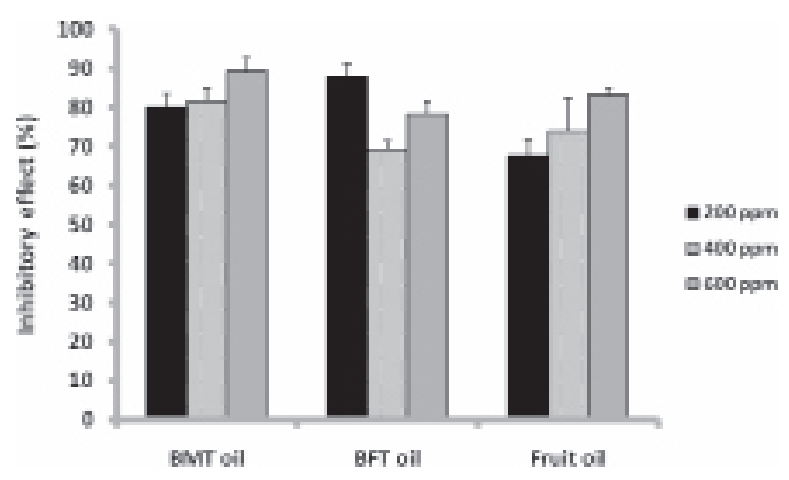

Figure 2. Inhibitory effects of Juniperus oblonga essential oils against insulin glycation. BMT: branchlets of male tree; BFT: branchlets of female tree.

\section{Linoleic acid peroxidation}

All three assessed oils could exert inhibitory activity against linoleic acid peroxidation and this was true for all tested concentrations and different time points. Overall, the inhibitory activity of oils decreased in the following order: BFT oil $>$ BMT oil $>$ fruit oil. For none of the tested oils there was an association between either concentration or duration of incubation and inhibitory effect (Table 3).

\section{Peroxyl radical mediated $R B C$ hemolysis}

Different degrees of in vitro anti-hemolytic activity was observed from all tested concentrations of BMT, BFT and fruit oils. The only exception was the effect of BFT oil at $260 \mu \mathrm{g} \cdot \mathrm{mL}^{-1}$ concentration, which was associated with an increase in RBC hemolysis. Overall, the anti-hemolytic activity of tested oils appeared to decrease in the following order: Fruit oil $>$ BMT oil $>$ BFT oil. No regular dose-dependent effect was observed for any of the tested oils (Table 4).

The results of the present study implied that essential oils obtained from BMT, BFT and fruits of $J$. oblonga possess antioxidant and anti-glycation capacities in different models that were employed i.d. LDL oxidation, linoleic acid peroxidation, RBC hemolysis, hemoglobin and insulin glycation assays.

Essential oils are well-documented for their antioxidant properties and hence nominated to be employed in food industry as natural alternatives for synthetic compounds such as BHA and BHT. Apart from their safety and lack of adverse effects such as hepatotoxicity and carcinogenesis, essential oils possess 
Table 3. Inhibitory effects of Juniperus sabina oils against linoleic acid peroxidation.

\begin{tabular}{ccccc}
\hline Concentration & Incubation time $(\mathrm{h})$ & BMT oil & BFT oil & Fruit oil \\
\hline \multirow{3}{*}{$480 \mathrm{ppm}$} & 1 & $42.38 \pm 2.00$ & $41.43 \pm 3.44$ & $38.10 \pm 1.27$ \\
& 2 & $18.18 \pm 9.85$ & $23.74 \pm 17.94$ & $44.95 \pm 1.20$ \\
& 3 & $28.97 \pm 4.96$ & $39.25 \pm 5.07$ & $37.38 \pm 1.20$ \\
$600 \mathrm{ppm}$ & 4 & $47.47 \pm 5.60$ & $39.63 \pm 2.02$ & $40.55 \pm 7.25$ \\
& 1 & $36.18 \pm 1.78$ & $39.20 \pm 5.09$ & $32.16 \pm 2.03$ \\
& 2 & $50.00 \pm 3.05$ & $47.56 \pm 8.03$ & $45.53 \pm 0.38$ \\
$720 \mathrm{ppm}$ & 3 & $44.35 \pm 3.41$ & $43.55 \pm 6.32$ & $51.61 \pm 2.28$ \\
& 4 & $47.48 \pm 1.70$ & $54.20 \pm 1.04$ & $37.39 \pm 10.62$ \\
\hline \multirow{3}{*}{} & 1 & $24.74 \pm 0.23$ & $30.93 \pm 9.38$ & $27.32 \pm 11.76$ \\
& 2 & $28.41 \pm 3.19$ & $38.64 \pm 11.21$ & $21.59 \pm 1.71$ \\
& 3 & $37.88 \pm 1.32$ & $38.38 \pm 7.07$ & $37.88 \pm 2.09$ \\
\hline
\end{tabular}

Values indicate inhibition percentage and are expressed as mean $\pm \mathrm{SD}(\mathrm{n}=3)$. BMT: branchlets of male tree; BFT: branchlets of female tree.

Table 4. Inhibitory effects of $J$. oblonga oils against peroxyl radical mediated RBC hemolysis.

\begin{tabular}{lccc}
\hline Concentration & $180 \mu \mathrm{g} \cdot \mathrm{mL}^{-1}$ & $220 \mu \mathrm{g} \cdot \mathrm{mL}^{-1}$ & $260 \mu \mathrm{g} \cdot \mathrm{mL}^{-1}$ \\
\hline BFT oil & $34.79 \pm 12.61$ & $26.79 \pm 12.18$ & $-33.70 \pm 24.05$ \\
BMT oil & $26.25 \pm 13.90$ & $43.81 \pm 8.63$ & $28.55 \pm 10.66$ \\
Fruit oil & $18.93 \pm 6.21$ & $48.16 \pm 12.70$ & $35.23 \pm 13.28$ \\
\hline
\end{tabular}

Values are expressed as $\%$ mean \pm SD $(n=3)$. BMT: branchlets of male tree; BFT: branchlets of female tree.

additional beneficial effects such as antimicrobial and anti-inflammatory properties (Sahebkar \& Iranshahi, 2010; Asili et al., 2009, 2010). Since terpenoid compounds constitute the majority of oil composition (Sahebkar \& Iranshahi, 2011; Emami et al., 2011) they are responsible for most of the observed biological activities of essential oils (Grassmann, 2005).

As far as we are aware, reports on the phytochemistry or biological activities of $J$. oblonga have been very scant. Emami and colleagues reported a strong antioxidant activity from fruits as well as leaves of male and female $J$. oblonga using ferrothiocyanate and thiobarbituric acid assays. In both mentioned methods, the antioxidant activities of $J$. oblonga oils were higher than $80 \%$ (Emami et al., 2007a). In another investigation, essential oils obtained from the same parts of $J$. oblonga were found to exert degrees of activity in DPPH radical scavenging and deoxyribose degradation assays (Emami et al., 2007b). In this latter study, phytochemical analysis of $J$. oblonga fruit and leaf oils revealed that $\alpha$-pinene, $\beta$-pinene and sabinene were the major components, each constituting $>10 \%$ of oil composition. Notably, this is very consistent with the findings of the present investigation in which the same compounds were found as the major components of BMT, BFT and fruit oils. There have also been some reports on the composition of $J$. oblonga essential oils from other parts of world indicating monoterpenes like $\alpha$-pinene, sabinene, limonene, terpinene-4-ol, and thujyl alcohol as principal components (Adams, 2000; Pisarev et al., 2005).

In the present study, BMT, BFT and fruit oils of $J$.oblonga were found to exert inhibitory activity against glycation of both hemoglobin and insulin. Protein glycation is implicated in the pathophysiology of several disorders including diabetes and atherosclerosis (Gugliucci, 2000; Price \& Knight, 2007). There is considerable evidence indicating the enhancement of protein glycation (via autoxidative glycation and glycoxidation) by oxidative stress (Wolff \& Dean, 1987; Wolff, 1993). Given this close nexus, antioxidants could play an important role in the prevention of protein glycation and its detrimental effects on body organs. In the hemoglobin glycation assay, the BMT oil showed the highest activity. Along with the possible role of unknown components (which needs to be clarified by further studies), this higher activity might be related to the relatively higher content of $\gamma$-terpinene in this oil compared to BMT and fruit oils. $\gamma$-terpinene is a monoterpene hydrocarbone which has recently attracted attention for its powerful antioxidant properties (Foti \& Ingold, 2003). Another important finding from the hemoglobin glycation assay was the inverse association between essential oil concentration and anti-glycation effects. This might be explained by the fact that at higher concentrations essential oil acts may act as oxygen-carrying agent and elicit pro-oxidant effects 
(Pérez et al., 2006; Gkinis et al., 2010; Miguel et al., 2010). Although the net effect of all oils at all tested concentrations was inhibitory, such a concentrationdependent dual activity could be hypothesized for some of the constituents of $J$. oblinga oils which leads to the aforementioned inverse association. However, this trend was not observed in the insulin glycation assays which could be attributed to the differences in the nature of assessed proteins (hemoglobin vs. insulin) that could affect on the ligand-protein interaction and thereby antiglycation effects. Apart from protein glycation, the tested oils could retard the oxidation of LDL. One of the most widely accepted hypotheses of atherosclerosis is based on the oxidative modification of LDL which triggers the process of atherogenesis (Berliner et al., 1995). Oxidized LDL has been shown to induce inflammatory response, monocyte chemotaxis and adhesion, endothelial cell migration, smooth muscle cell proliferation and etc, all being influential in the development and progression of atherosclerosis (Navab et al., 1995; Geng \& Libby, 1995; Steinberg, 1997; Chisolm \& Steinberg, 2000). Therefore, inhibition of oxidized LDL formation could halt the process of atherogenesis in its early stages. In consistence with these observations, all three tested oils showed inhibitory activity against peroxyl radical mediated $\mathrm{RBC}$ hemolysis. The only exception was the highest concentration of BFT oil for which a pro-oxidant effect was observed. This prooxidant effect could be explained by the same reason stated earlier for the hemoglobin glycation assay. Furthermore, in the phytochemical analysis, some volatile compounds were found to be more abundant in the BFT vs. BMT and fruit oils. An example is limonene which might act as pro-oxidant at higher concentrations. Another possible explanation for this finding is the role of unknown components. As shown in Table 1, the amount of unknown compounds in the BFT oil is considerably higher than the other two oils. While these unknown components are to be identified by future investigations, some of them might be responsible for the observed pro-oxidant effects of the BFT oil at the higher concentration.

Oxidative degradation of biological lipids, in particular polyunsaturated fatty acids such as linoleic acid, is an important feature of oxidative stress injury that results in severe cellular dysfunction. On the other hand, lipid peroxidation generates several cytotoxic end products such as hydroperoxide-derived aldehydes which could spread free radical reactions and oxidative injury throughout the body and thereby cause deleterious effects such as mutagenesis, carcinogenesis and hemolysis (Esterbauer et al., 1991; Marnett, 1999). An interesting finding of the present research was inhibition of linoleic acid by all three tested oils. This effect could be attributed, at least in part, to the radical scavenging activity which has been previously reported for the same oils (Emami et al., 2007b).

In summary, the findings of the present study indicated that essential oils obtained from the fruits and branchlets of $J$. oblonga possess antioxidant and antiglycation properties. These findings contribute additional evidence on the biological activities of essential oils and their potential to be applied in medicine and food processing. Further research should be done to investigate whether the antioxidant activities of J. oblonga oils could be extrapolated into the in vivo situations. To this end, evaluation of anti-diabetic and anti-atherosclerotic effects of these oils as well as their impact on the well-known biomarkers of oxidative stress such as malondialdehyde and isoprostanes could be helpful. Furthermore, studies are required to screen the anti-glycation activities of these oils against a wider panel of proteins and also test a broader spectrum of oil concentrations. Finally, confirmation of the type and relative abundance of essential oil components as well as safety assessment of $J$. oblonga oils are other issue that deserves to be investigated.

\section{Acknowledgements}

The authors would like to thank the authorities of the Mashhad University of Medical Sciences (MUMS) research council as well as authorities of the Isfahan University of Medical Sciences (IUMS) for their respective supports. The authors also wish to express their sincerest gratitude to Mrs. A. Jamshidi for her kind helps.

\section{References}

Adams RP 2000. Systematics of Juniperus section Juniperus based on leaf essential oils and random amplified polymorphic DNAs (RAPDs). Biochem Syst Ecol 28: 515-528.

Adams RP 2001. Identification of essential oils components by gas chromatography/quadrapole mass spectroscopy. Carol Stream: Allured Publishing Corp.

Anderson JW, Gowri MS, Turner J, Nichols L, Diwadkar VA, Chow CK, Oeltgen PR 1999. Antioxidant supplementation effects on low-density lipoprotein oxidation for individuals with type 2 diabetes mellitus. $J$ Am Coll Nutr 18: 451-461.

Asgary S, Naderi GA, Sarraf-Zadegan N, Vakili R 2002. The inhibitory effects of pure flavonoids on in vitro protein glycosylation. $J$ Herb Pharmacother 2: 47-55.

Asili J, Sahebkar A, Fazly-Bazzaz BS, Sharifi S, Iranshahi M 2009. Identification of essential oil components of Ferula badrakema fruits by GC-MS and 13C-NMR methods and evaluation of its antimicrobial activity. $J$ Essent Oil Bear Pl 12: 7-15

Asili J, Emami SA, Rahimizadeh M, Fazly-Bazzaz BS, 
Hassanzadeh MK 2010. Chemical and antimicrobial studies of Juniperus sabina L. and Juniperus foetidissima Willd. essential oils. J Essent Oil Bear Pl 13: 25-36.

Berliner JA, Navab M, Fogelman AM, Frank JS, Demer LL, Edwards PA, Watson AD, Lusis AJ 1995. Atherosclerosis: basic mechanisms. Oxidation, inflammation, and genetics. Circulation 91: 2488-2496.

Chisolm GM, Steinberg D 2000. The oxidative modification hypothesis of atherogenesis: an overview. Free Radical Bio Med 28: 1815-1826.

Drabkin HJ, Helk B, RajBhandary UL 1993. The role of nucleotides conserved in eukaryotic initiator methionine tRNAs in initiation of protein synthesis. $J$ Biol Chem 268: 25221-25228.

Emami SA, Asili J, Mohagheghi Z, Hassanzadeh MK 2007a. Antioxidant activity of leaves and fruits of Iranian conifers. Evid-Based Compl Alt 4: 313-319.

Emami SA, Javadi B, Hassanzadeh MK 2007b. Antioxidant activity of the essential oils of different parts of Juniperus communis subsp. hemisphaerica and Juniperus oblonga. Pharm Biol 45: 769-776.

Emami SA, Asgary S, Naderi GA, Shams Ardekani MR, Kasher T, Aslani S, Airin A, Sahebkar A 2011. Antioxidant activities of Juniperus foetidissima essential oils against several oxidative systems. Rev Bras Farmacogn 21: 627-634.

Esterbauer H, Schaur RJ, Zollner H 1991. Chemistry and biochemistry of 4-hydroxynonenal, malonaldehyde and related aldehydes. Free Radical Bio Med 11: 81-128.

Farag RS, Badei AZMA, Hewedi FM, El-Baroty GSA 1989. Antioxidant activity of some spice essential oils on linoleic acid oxidation in aqueous media. J Am Oil Chem Soc 66: 792-799.

Foti, MC, Ingold KU 2003. Mechanism of inhibition of lipid peroxidation by gamma-terpinene, an unusual and potentially useful hydrocarbon antioxidant. J Agric Food Chem 51: 2758-2765.

Geng YJ, Libby P 1995. Evidence for apoptosis in advanced human atheroma. Colocalization with interleukin-1 beta converting enzyme. Am J Pathol 147: 251-266.

Gkinis G, Bozin B, Mimica-Dukic N, Tzakou O 2010. Antioxidant activity of Nepeta nuda L. ssp. nuda essential oil rich in nepetalactones from greece. $J$ Med Food 13: 1176-1181.

Grassmann J 2005. Terpenoids as plant antioxidants. Vitam Horm 72: 505-535.

Grice HP 1988. Enhanced tumour development by butylated hydroxyanisole (BHA) from the prospective of effect on fore-stomach and oesophageal squamous epithelium. Food Chem Toxicol 26: 717-723.

Gugliucci A 2000. Glycation as the glucose link to diabetic complications. J Am Osteopath Assoc 100: 621-634.

Kang HJ, Chawla SP, Jo C, Kwon JH, Byun MW 2006. Studies on the development of functional powder from citrus peel. Bioresource Technol 97: 614-20.
Komarov VL 1968. Flora of U.S.S.R. Vol. 1. Jerusalem: Programs for Scientific Translations.

Ljubuncic P, Dakwar S, Portnaya I, Cogan U, Azaizeh H, Bomzon A 2006. Aqueous extracts of Teucrium polium possess remarkable antioxidant activity in vitro. EvidBased Compl Alt 3: 329-338.

Lowry OH, Rosebrough NJ, Farr AL, Randall RJ 1951. Protein measurement with the Folin phenol reagent. $J$ Biol Chem 193: 265-275.

Marnett LJ 1999. Lipid peroxidation-DNA damage by malondialdehyde. Mutat Res 424: 83-95.

Miguel MG, Cruz C, Faleiro L, Simões MTF, Figueiredo AC, Barroso JG, Pedro LG 2010. Foeniculum vulgare essential oils: Chemical composition, antioxidant and antimicrobial activities. Nat Prod Commun 5: 319-328.

Monnier VM 1990. Nonenzymatic glycosylation, the Maillard reaction and the aging process. J Gerontol 45: 105-111.

Navab M, Fogelman AM, Berliner JA, Territo MC, Demer LL, Frank JS, Watson AD, Edwards PA, Lusis AJ 1995. Pathogenesis of atherosclerosis. Am J Cardiol 76: 18C$23 \mathrm{C}$.

Pérez Gutiérrez RM, Luna HH, Garrido SH 2006. Antioxidant activity of Tagetes erecta essential oil. J Chil Chem Soc 51: 883-886.

Pisarev DI, Denisenko ON, Pyatigorsk GOS 2005. The composition of essential oils in Juniper (Juniperus oblonga) needles and fruits. Farm Akad Russia Farmatsiya 1: 12-14.

Price CL, Knight SC 2007. Advanced glycation: a novel outlook on atherosclerosis. Curr Pharm Design 13: 3681-3687.

Sahebkar A, Iranshahi M 2010. Biological activities of essential oils from the genus Ferula (Apiaceae). Asian Biomed 4: 835-847.

Sahebkar A, Iranshahi M 2011. Volatile constituents of the genus Ferula (Apiaceae): A review. $J$ Essent Oil-Bear Plants 14: 504-531.

Schinella GR, Tournier HA, Manez S, de Buschiazzo PM, del Carmen Recio M, Rios JL 2007. Tiliroside and gnaphaliin inhibit human low density lipoprotein oxidation. Fitoterapia 78: 1-6.

Selvaraj N, Bobby Z, Das AK, Ramesh R, Koner BC 2002. An evaluation of level of oxidative stress and protein glycation in nondiabetic undialyzed chronic renal failure patients. Clin Chim Acta 324: 45-50.

Steinberg D 1997. Low-density lipoprotein oxidation and its pathobiological significance. J Biol Chem 272: $20963-$ 20966.

Valenzuela A, Guerra R, Videla LA 1986. Antioxidant properties of the flavonoids silybin and (+)-cyanidanol-3: Comparison with butylated hydroxyanisole and butylated hydroxytoluene. Planta Med 6: 438-440.

van Ginkel G, Sevanian A 1994. Lipid peroxidation induced membrane structural alterations. Method Enzymol 233: 273-288.

Wang R, Wei W, Wang L, Liu R, Yi D, Du L 2006. Constituents 
of the flowers of Punica granatum. Fitoterapia 77: 534537.

Wichi HC 1986. Safety evaluation of butylated hydroxytoluene (BHT) in the liver, lung and gastrointestinal tract. Food Chem Toxicol 24: 1127-1130.

Wolff SP, Dean RT 1987. Glucose autoxidation and protein modification: potential role of autooxidative glycosylation in diabetes. Biochem J 245: 243-250.

Wolff SP 1993. Diabetes Mellitus and free radicals: free radicals, transition metals and oxidative stress in the etiology of diabetes mellitus and complications. Brit Med Bull 49: 642-652.

\section{*Correspondence}

Seyed Ahmad Emami

Department of Pharmacognosy, School of Pharmacy, Mashhad University of Medical Sciences, Mashhad, Iran

emamia@mums.ac.ir

Tel.: +98-511-8823255 